\title{
Promoted Iron Nanocrystals Obtained via Ligand Exchange as Active and Selective Catalysts for Synthesis Gas Conversion
}

Marianna Casavola, ${ }^{\|, \perp}$ Jingxiu Xie, ${ }^{\|, \dagger}$ Johannes D. Meeldijk, ${ }^{\|}$Nynke A. Krans, ${ }^{\|}$Andrey Goryachev, Jan P. Hofmann, ${ }^{\ddagger}$ A. Iulian Dugulan, ${ }^{\S}$ and Krijn P. de Jong*,

"Inorganic Chemistry and Catalysis, Debye Institute for Nanomaterials Science, Utrecht University, Universiteitsweg 99,3584 CG Utrecht, The Netherlands

${ }^{\ddagger}$ Laboratory of Inorganic Materials Chemistry, Department of Chemical Engineering and Chemistry, Eindhoven University of Technology, Postbox 513, 5600 MB Eindhoven, The Netherlands

${ }^{\S}$ Fundamental Aspects of Materials and Energy Group, Delft University of Technology, Mekelweg 15, 2629 JB Delft, The Netherlands

Supporting Information

ABSTRACT: Colloidal synthesis routes have been recently used to fabricate heterogeneous catalysts with more controllable and homogeneous properties. Herein a method was developed to modify the surface composition of colloidal nanocrystal catalysts and to purposely introduce specific atoms via ligands and change the catalyst reactivity. Organic ligands adsorbed on the surface of iron oxide catalysts were exchanged with inorganic species such as $\mathrm{Na}_{2} \mathrm{~S}$, not only to provide an active surface but also to introduce controlled amounts of $\mathrm{Na}$ and $\mathrm{S}$ acting as promoters for the catalytic process. The catalyst composition was optimized for the Fischer-Tropsch direct conversion of synthesis gas into lower olefins. At industrially relevant conditions, these nanocrystal-based catalysts with controlled composition were more active, selective, and stable than catalysts with similar composition but synthesized using conventional methods, possibly due to their homogeneity of properties and synergic interaction of iron and promoters.

KEYWORDS: Fischer-Tropsch to olefins, iron-based catalysts, colloidal nanocrystals, ligand exchange, iron oxide

\section{INTRODUCTION}

Supported metal nanoparticles have a wide range of applications, varying from drug delivery to heterogeneous catalysis. ${ }^{1-3}$ In particular, supported metal nanoparticles pave a route to rational catalyst design, and design strategies include optimal metal-support interaction, interparticle distance, uniform particle size, structure, and morphology. ${ }^{4-7}$ Established preparation methods such as precipitation (coprecipitation or deposition precipitation) and impregnation (incipient wetness impregnation or wet impregnation) are commonly used; however, other techniques including melt infiltration, colloidal synthesis, atomic layer deposition, and metal-organic frameworks have become increasingly popular. ${ }^{8}$

To improve the catalytic performance of supported metal nanoparticles, other elements are often added, and they can be classified as structural, electronic, or reduction promoters. ${ }^{9,10}$ Ideally, promoters should be in close proximity with the catalytic active metal surface, but this is usually not achieved as promoters also deposit on the support surface. The promoters are typically introduced to supported catalytic systems via impregnation or coprecipitation with promoter metal salt precursor solution, and the drawback is a lack of control on the location of the promoters. However, strong electrostatic adsorption and controlled surface reactions (catalytic reduction or direct redox reaction) methods were proven to introduce promoters selectively onto the catalytically active metal surface. ${ }^{11,12}$

The increase in global demand for lower olefins (ethylene, propylene, butylenes) coupled with the regional diversification of carbon raw materials brings about opportunities for emerging technologies. ${ }^{13}$ The alternative carbon feedstocks, including coal, natural gas, and biomass, can first be converted to synthesis gas, a mixture of $\mathrm{CO}$ and $\mathrm{H}_{2} \cdot{ }^{14,15}$ Synthesis gas can subsequently be used to produce fuels and chemicals, including lower olefins and oxygenates. ${ }^{16-18}$ The commercial production of lower olefins from synthesis gas is via methanol (methanolto-olefins), ${ }^{19,20}$ but direct routes, namely, oxide-zeolite (OXZEO) $)^{21,22}$ and Fischer-Tropsch to olefins (FTO), ${ }^{23}$ offer potentially higher efficiencies in volume, energy, materials, plant operations, and cost. The Fischer-Tropsch synthesis (FTS), recognized to be structure-sensitive and promoter-dependent, is a surface polymerization reaction, and its product distribution can be described using the Anderson-Schulz-Flory (ASF) model. $^{24,25}$ Promoted iron-based catalysts ${ }^{26,27}$ as well as cobaltbased catalysts ${ }^{28}$ are promising candidates for the FTO reaction at elevated temperature.

Received: March 16, 2017

Revised: May 19, 2017

Published: June 19, 2017 
Typical promoters for Fe-based catalysts include, $\mathrm{K}, \mathrm{Cu}, \mathrm{Mn}$, $\mathrm{Na}$, and $\mathrm{S}$, and they are introduced via coimpregnation or coprecipitation of promoter precursor. ${ }^{29-31}$ Recently, Sasol presented the effects of various promoters on 306 bulk-Fe catalysts prepared via precipitation. ${ }^{32}$ It was concluded that bulk-Fe catalysts with $\mathrm{Na} / \mathrm{S} \geq 2$ performed best in terms of activity and selectivity toward lower olefins, which is in line with Torres Galvis et al. ${ }^{26}$ However, this study was performed on bulk-Fe catalysts, and the promotion effects on supported Fe-based catalysts require more investigation. As catalysts are synthesized by coprecipitation or coimpregnation of the different species, determining the amount of the different atoms per nanoparticle and their arrangement in the catalyst nanoparticle structure remains a challenge. This suggests that new strategies are required to incorporate promoters in catalyst nanoparticles in a controlled way to obtain nanocrystals (NCs) with a homogeneous composition.

NCs prepared by colloidal synthesis, offer delicate control over size, shape, composition, crystal structure, and surface properties. ${ }^{33}$ Thus, they are promising and appealing building blocks for advanced materials and devices, including hydrogen storage, electronics, drug delivery, and catalysis. ${ }^{34-36}$ In particular, NCs were used to study structure sensitivities ${ }^{37,38}$ and metal-support interfaces in catalytic applications. ${ }^{39}$

We recently demonstrated that colloidal NCs with very narrow size dispersion (10\% standard deviation) and tunable size in the 3-20 nm range can be successfully used to fabricate active heterogeneous catalysts with exceptional stability. ${ }^{40}$ The performance of these catalysts could be improved by the incorporation of promoter species on their surface, but this cannot be achieved with conventional methods. The key characteristic of colloidal NC is that they are capped with a layer of surfactants, which are essential to control their growth but hinder their implementation in devices and other applications. Therefore, a considerable scientific effort is devoted to develop methods to eliminate ligands while preserving NC stability. ${ }^{41,42}$ On the other hand, the presence of ligands makes the NC surface a very versatile platform, ${ }^{43}$ and they even can be used as active agents to direct a catalytic process. ${ }^{44}$ In addition, ligands can be advantageously replaced with other species (ligand exchange) to modify the surface properties of NCs and make them suitable for specific applications, such as biocompatible polymer-coated ${ }^{45}$ and photochromic cluster-functionalized NCs. ${ }^{46}$

Interestingly, it has been demonstrated that it is possible to replace the long-chain ligands on the NC surface with inorganic charged species, such as chalcogenides, $\mathrm{OH}^{-}$, and amide ions. ${ }^{3,47-49}$ Herein we propose to use $\mathrm{Na}_{2} \mathrm{~S}$ and $\mathrm{NaHS}$ to replace organic ligands and to drive $\mathrm{Na}$ and $\mathrm{S}$ promoter species adsorption on the NC surface. By using the inorganic ligand exchange strategy, it is possible to direct promoters onto the catalytically active metal surface and provide a route to tune promoter concentration on the metal. For this purpose, catalysts based on iron oxide NCs supported on carbon nanotubes (CNTs) were treated with a solution of $\mathrm{Na}_{2} \mathrm{~S}$ to replace the conventional oleate surfactants with $\mathrm{Na}_{2} \mathrm{~S}$, acting as an inorganic ligand. This strategy has the additional advantage of eliminating carbon-rich ligands which could deactivate the catalyst.

The synthesized catalysts, consisting of iron oxide NC with uniform size and distribution on the CNT support as well as controllable composition in promoters, were characterized with inductively-coupled plasma atomic emission spectrometry
(ICP-AES), X-ray photoelectron spectroscopy (XPS), scanning transmission electron microscopy-energy-dispersive X-ray spectroscopy (STEM-EDX), and in situ Mössbauer spectroscopy. The catalytic performance of these catalysts was compared with that of conventional catalysts at industrially relevant conditions ( $340{ }^{\circ} \mathrm{C}$ and 10 bar).

\section{EXPERIMENTAL METHODS}

Synthesis of Colloidal NC Catalysts. General Procedure. Iron oxide NCs of $7 \mathrm{~nm}$ diameter were synthesized according to literature procedures based on the aminolysis/ alcholysis of iron oleate. ${ }^{50-53}$ The as-synthesized, mainly oleatecapped, iron oxide NCs were then anchored to a CNT support, successively treated with $\mathrm{Na}_{2} \mathrm{~S}$ and dried. A detailed description of the different synthesis paths is reported below.

Synthesis of $7 \mathrm{~nm} \mathrm{Fe} \mathrm{NC.}{ }^{40}$ All chemicals were purchased from Sigma-Aldrich and were used as received. Initially, $0.43 \mathrm{~g}$ of oleic acid $\left(\mathrm{C}_{17} \mathrm{H}_{33} \mathrm{CO}_{2} \mathrm{H}\right.$ or OLAC, $\left.90 \%\right), 0.21 \mathrm{~g}$ of oleylamine $\left(\mathrm{C}_{17} \mathrm{H}_{33} \mathrm{NH}_{2}\right.$ or OLAM, $\left.70 \%\right)$, and $0.35 \mathrm{~g}$ of 1,2 hexadecanediol $\left(\mathrm{C}_{16} \mathrm{H}_{33}(\mathrm{OH})_{2}, \geq 98 \%\right)$ in $10 \mathrm{~mL}$ of 1 octadecene $\left(\mathrm{C}_{18} \mathrm{H}_{36}\right.$ or ODE, $\left.90 \%\right)$ were mixed in a $100 \mathrm{~mL}$ three-neck round-bottom flask. The flask was connected to a Schlenk line through a reflux cooler. The mixture (magnetically stirred at $650 \mathrm{rpm}$ ) was degassed for $30 \mathrm{~min}$ at $120^{\circ} \mathrm{C}$ under vacuum and subsequently purged with nitrogen flow. The temperature was lowered to $90{ }^{\circ} \mathrm{C}$ before $0.21 \mathrm{~g}$ of iron pentacarbonyl (Aldrich, 99.99\%) in $1 \mathrm{~mL}$ of octadecene was injected. The temperature was then increased to $290{ }^{\circ} \mathrm{C}$ at a rate of $20^{\circ} \mathrm{C}$ per minute, and the mixture was refluxed for $1 \mathrm{~h}$. The mixture was cooled to room temperature and further processed in air. The NC suspension was purified by three cycles of dispersion in $200 \mu \mathrm{L}$ of toluene and precipitation in isopropanol; centrifugation at $2500 \mathrm{rpm}$ for $15 \mathrm{~min}$ was necessary to separate the NC from organic solution after each cycle.

Attachment of $7 \mathrm{~nm}$ Fe NC on CNT (Approximately $3 \mathrm{wt}$ $\%$ Fe Loading). ${ }^{40,54}$ The synthesized Fe NC and $800 \mathrm{mg}$ multiwalled CNT (Bayer, Baytubes C $150 \mathrm{HP}$, from 5 to $30 \mathrm{~nm}$ external diameter, sieve fraction $212-425 \mu \mathrm{m}$ ) were suspended in $10 \mathrm{~mL}$ of octadecene in a $100 \mathrm{~mL}$ three-neck round-bottom flask. The mixture (magnetically stirred at $400 \mathrm{rpm}$ ) was degassed for $30 \mathrm{~min}$ at $120^{\circ} \mathrm{C}$ under vacuum and subsequently purged with nitrogen flow. The temperature was increased to $200{ }^{\circ} \mathrm{C}$ under nitrogen flow and kept at this temperature for 0.5 h. The mixture was then cooled to room temperature and further processed in air. The Fe NC supported on CNT catalyst was washed 5 times with hexane and acetone (ratio 1:3) and finally dried at $60{ }^{\circ} \mathrm{C}$ for $1 \mathrm{~h}$ under static air, $120{ }^{\circ} \mathrm{C}$ for $3 \mathrm{~h}$ under static air, and $80{ }^{\circ} \mathrm{C}$ for $3 \mathrm{~h}$ under vacuum.

Promotion using $\mathrm{Na}_{2} \mathrm{~S}$ Inorganic Ligand Exchange. In the first step, $0.24 \mathrm{~g}$ of sodium sulfide nonahydrate ( $\geq 98 \%)$ was sonicated in $20 \mathrm{~mL}$ of formamide ( $\geq 99.5 \%)$ for $1 \mathrm{~h}$ to obtain a $0.05 \mathrm{M}$ stock solution. In order to have a molar ratio of $\mathrm{Na}_{2} \mathrm{~S}$ / $\mathrm{Fe}=1,100 \mathrm{mg}$ of the synthesized Fe NC on CNT catalyst was added into $1.2 \mathrm{~mL}$ of $0.05 \mathrm{M}$ stock solution and magnetically stirred at $400 \mathrm{rpm}$ for $10 \mathrm{~min}$. The molar concentration of the $\mathrm{Na}_{2} \mathrm{~S}$ solution was decreased to obtain lower promotion levels of $\mathrm{Na}_{2} \mathrm{~S} / \mathrm{Fe}=0.5,0.25$, and 0.1. Catalyst $\mathrm{cFeP0} .5$ was prepared with $\mathrm{Na}_{2} \mathrm{~S} / \mathrm{Fe}=0.5$. After the inorganic $\mathrm{Na}_{2} \mathrm{~S}$ exchange step, the following washing procedure was used: $1 \times$ ethanol, $4 \times$ ethanol and acetone (ratio 1:3), and $1 \times$ acetone. Finally, the drying procedure was $1 \mathrm{~h}$ under static air, $120^{\circ} \mathrm{C}$ for $3 \mathrm{~h}$ under static air, and room temperature for $3 \mathrm{~h}$ under vacuum. 
Synthesis of Reference Catalysts. The reference catalysts were prepared using incipient wetness impregnation (IWI). To synthesize the unpromoted $3 \mathrm{wt} \%$ Fe reference catalyst, 0.207 $\mathrm{g}$ of ammonium iron citrate (Fluka, purum p.a., 14.5-16 wt \% $\mathrm{Fe}$ ) was first dissolved in $0.5 \mathrm{~mL}$ of demineralized water and $0.25 \mathrm{~mL}$ of methanol (Aldrich, 99.8\%) was then added. This solution was impregnated in a single step on to $1.0 \mathrm{~g}$ of CNT, and the sample was dried in static air at $120{ }^{\circ} \mathrm{C}$ for $2 \mathrm{~h}$. Heat treatment was performed at $500{ }^{\circ} \mathrm{C}$ for $2 \mathrm{~h}\left(5{ }^{\circ} \mathrm{C} / \mathrm{min}\right.$; 100 $\mathrm{mL} / \mathrm{min}$ for $1 \mathrm{~g}$ catalyst) under nitrogen flow, and after the catalyst was cooled to room temperature, it was passivated by increasing oxygen concentration stepwise $(2 \% \mathrm{v} / \mathrm{v}$ increase every $30 \mathrm{~min}$ ) until reaching $20 \% \mathrm{v} / \mathrm{v}$. To synthesize the promoted 3 wt $\%$ Fe reference catalyst, $0.202 \mathrm{~g}$ of ammonium iron citrate (Fluka, purum p.a., 14.5-16 wt \% Fe), $0.004 \mathrm{~g}$ of sodium citrate tribasic dihydrate (Aldrich, $\geq 99 \%$ ) and $0.005 \mathrm{~g}$ of iron(II) sulfate heptahydrate (Aldrich, $\geq 99 \%$ ) were used, and the procedure was followed as described above. The reference catalysts were coded $\mathrm{iFe}$ and $\mathrm{iFeP0.5}$, which indicate unpromoted and promoted $\mathrm{Fe}$ nanoparticles on CNT, respectively.

Characterization. The elemental loadings of Fe, $\mathrm{Na}$, and $\mathrm{S}$ were determined with a Thermo Jarrell Ash model ICAP 61E trace analyzer ICP-AES. Thermo gravimetric analysis-mass spectrometry (TGA-MS) was used to determine the metal loadings and to verify the presence of organic ligands, which give rise to a mass loss at $200-300{ }^{\circ} \mathrm{C}$ and specific MS peaks. Transmission electron microscopy (TEM) was used to determine the iron particle size distribution and the spatial distribution of iron nanoparticles on the support, before and after catalytic tests. Scanning transmission electron microscopyhigh angle annular dark field (STEM-HAADF) images and EDX analyses were obtained with an FEI Talos F200X transmission electron microscope, operated at $200 \mathrm{kV}$ and equipped with a high-brightness field emission gun (X-FEG) and a Super-X G2 EDX detector. XPS spectra were acquired on a Thermo Scientific K-Alpha spectrometer using an Al K $\alpha(h \nu$ $=1486.6 \mathrm{eV}$ ) monochromatic small-spot X-ray source operated at $75 \mathrm{~W}$. Charging effects were corrected by using the adventitious carbon $\mathrm{C} 1 \mathrm{~s}\left(\mathrm{sp}^{3}\right)$ peak as reference for all samples at a binding energy (BE) of $284.8 \mathrm{eV}$. Fitting of the spectra (BE, fwhm, peak shape, asymmetry, number of species) was performed with CasaXPS. The composition of the $\mathrm{Fe}$ phases before reaction, after reduction, and at various FTO conditions was determined in situ with transmission ${ }^{57} \mathrm{Fe}$ Mössbauer spectroscopy. ${ }^{57} \mathrm{Fe}$ Mössbauer spectra were collected at $4.2 \mathrm{~K}$ with a sinusoidal velocity spectrometer using a ${ }^{57} \mathrm{Co}(\mathrm{Rh})$ source. Velocity calibration was carried out using an $\alpha$-Fe foil at room temperature. The temperature of the source and the absorbing samples were kept identical during the measurements. The Mössbauer spectra were fitted using the Mosswinn 4.0 program. ${ }^{55}$ The experiments were performed identically as a catalytic test in a state-of-the-art high-pressure Mössbauer in situ cell. ${ }^{56}$ The high-pressure beryllium windows used in this cell contain $0.08 \%$ Fe impurity whose spectral contribution was fitted and removed from the final spectra.

Catalyst Performance. Catalytic experiments were performed using a high throughput 16 parallel fixed-bed reactors setup (Flowrence, Avantium). Each reactor was loaded with 20 $\mathrm{mg}$ of catalyst $(212-425 \mu \mathrm{m})$ and $200 \mathrm{mg} \mathrm{SiC}(212-425 \mu \mathrm{m})$ as diluent, except iFe in which $80 \mathrm{mg}$ catalyst and $50 \mathrm{mg} \mathrm{SiC}$ were loaded, so as to attain similar catalyst bed lengths and $\mathrm{CO}$ conversions of $25-45 \%$ after $100 \mathrm{~h}$. The catalysts were first reduced in situ at $340{ }^{\circ} \mathrm{C}\left(5^{\circ} \mathrm{C} / \mathrm{min}\right), 3 \mathrm{bar}, \mathrm{He} / \mathrm{H}_{2}=2$, GHSV $=3600 \mathrm{~h}^{-1}$ for $2 \mathrm{~h}$. The synthesis gas mixture $\left(\mathrm{H}_{2} / \mathrm{CO} / \mathrm{He}=\right.$ $60 / 30 / 10)$ with GHSV $=3600 \mathrm{~h}^{-1}$ was introduced at $280{ }^{\circ} \mathrm{C}$ and $3 \mathrm{bar}$, and temperature and pressure were subsequently increased to $340{ }^{\circ} \mathrm{C}\left(2{ }^{\circ} \mathrm{C} / \mathrm{min}\right)$ and 10 bar. The product stream was analyzed using online gas chromatography (Agilent $7890 \mathrm{~A})$. Hydrocarbons $\left(\mathrm{C}_{1}-\mathrm{C}_{9}\right)$ were separated on an Agilent J\&W PoraBOND Q column, detected using an FID detector and quantified against the TCD signal of the internal standard $\mathrm{He}$. The permanent gases $\left(\mathrm{CO}, \mathrm{H}_{2}, \mathrm{He}, \mathrm{CO}_{2}\right.$, and $\left.\mathrm{CH}_{4}\right)$ were separated on a ShinCarbon ST (no. 19043) column and quantified against $\mathrm{He}$ as an internal standard using a TCD detector. Catalytic activity, in terms of iron time yield (FTY), was expressed as moles of $\mathrm{CO}$ converted per gram of Fe per second. $\mathrm{CO}$ conversion $(\%)$ was calculated as $X_{\mathrm{CO}}=\left(\mathrm{mol}_{\mathrm{CO}}\right.$ in $\left.-\operatorname{mol}_{\mathrm{CO} \text { out }}\right) / \mathrm{mol}_{\mathrm{CO} \text { in }}$. The product selectivity to hydrocarbons up to $\mathrm{C}_{9}$ was determined with online gas chromatography (GC) and was calculated on a carbon atom basis. Selectivity toward $\mathrm{CO}_{2}$ was also measured.

\section{RESULTS AND DISCUSSION}

An overview of the fresh catalysts and their properties is presented in Table 1. Different batches of catalysts were

Table 1. Properties of Promoted and Unpromoted CNTSupported Fe-Based Catalysts

\begin{tabular}{|c|c|c|c|c|c|c|}
\hline & \multicolumn{3}{|c|}{ bulk weight loading (wt \%) ${ }^{a}$} & \multicolumn{3}{|c|}{ surface atomic ratio ${ }^{b}$} \\
\hline & $\mathrm{Fe}$ & $\mathrm{Na}$ & $S$ & $\mathrm{Na} / \mathrm{Fe}$ & $\mathrm{S} / \mathrm{Fe}$ & $\mathrm{Na} / \mathrm{S}$ \\
\hline CNT & 0.0 & 0.06 & - & - & - & - \\
\hline $\mathrm{iFe}$ & 2.7 & - & - & - & - & - \\
\hline iFeP0.5 & 2.9 & 0.13 & 0.04 & - & - & - \\
\hline $\mathrm{cFe}$ & 2.7 & 0.04 & - & 0 & 0 & 0 \\
\hline cFeP0.1 & 3.2 & 0.08 & 0.03 & - & - & - \\
\hline cFeP0.25 & 3.2 & 0.10 & 0.03 & 0.03 & 0.02 & 1.3 \\
\hline cFeP0.5 & 2.9 & 0.14 & 0.06 & 0.04 & 0.03 & 1.7 \\
\hline cFeP1.0 & 2.4 & 0.18 & 0.08 & 0.05 & 0.03 & 2.0 \\
\hline cFeP0.5-iwi & 2.5 & 0.16 & 0.04 & - & - & - \\
\hline
\end{tabular}

synthesized using the identical procedure and their elemental loadings are included in Table S1. Trace amounts of Na were found in blank CNT support and that might result in variations of $\mathrm{Na}$ loadings in the catalysts.

The promotion level was altered by varying the molar concentration of the $\mathrm{Na}_{2} \mathrm{~S}$ solution while keeping the other parameters (e.g., duration, stirring rate, volume, and temperature) constant. Increasing the molar concentration of the $\mathrm{Na}_{2} \mathrm{~S}$ solution to increase the promotion level was successful, as determined by the increased $\mathrm{Na}$ and $\mathrm{S}$ elemental loadings. It is noteworthy to point out that after correcting for $\mathrm{Na}$ present in the blank $\mathrm{CNT}$, the $\mathrm{Na} / \mathrm{S}$ molar ratio for all promoted catalysts was close to 2, as in the $\mathrm{Na}_{2} \mathrm{~S}$ precursor. This indicates that both $\mathrm{Na}$ and $\mathrm{S}$ are adsorbed at the catalyst surface. XPS measurements proved that there were indeed increased $\mathrm{Na}$ and $S$ concentration on the surface, as the peak intensities of $S 2 p$ (Figure S1a) and Na 1s (Figure S1b) increased upon increasing promotion. The $S 2 p$ peak positions indicated the presence of oxidized sulfur species such as sulfate $\left(\mathrm{S}^{4+}\right.$ or $\left.\mathrm{S}^{6+}, \sim 168 \mathrm{eV}\right)$ as well as reduced species $\left(\mathrm{S}^{0}\right.$ to $\left.\mathrm{S}^{2-}, \sim 164 \mathrm{eV}\right)$ for the promoted catalysts, implying the oxidation of reduced $S$ species upon air 

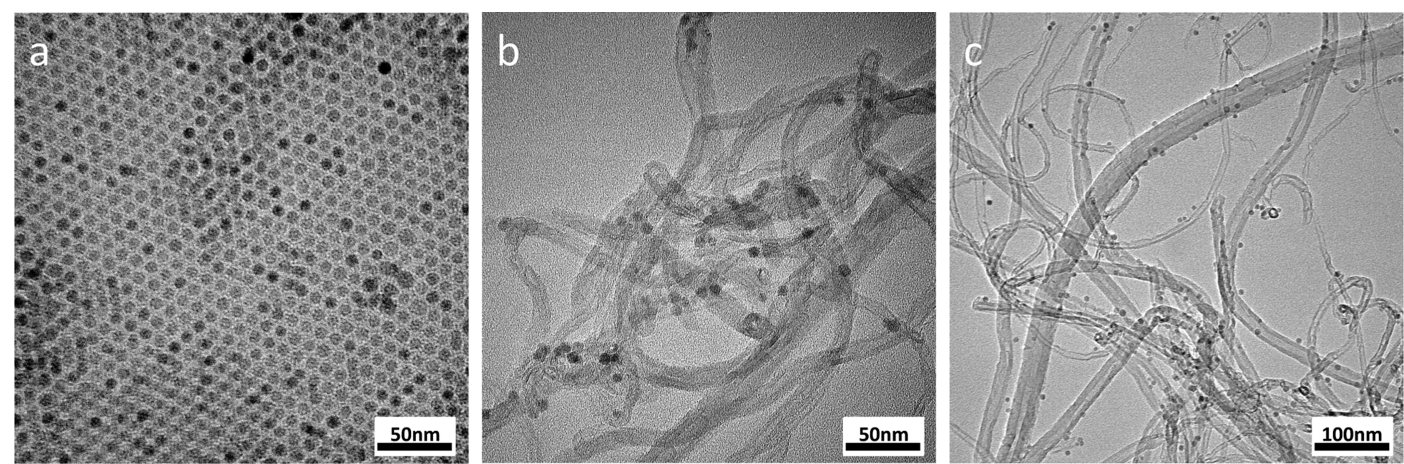

Figure 1. TEM images of cFeP0.5 (a) $7 \mathrm{~nm}$ Fe NC, (b) and (c) $7 \mathrm{~nm}$ Fe NC attached on CNT and promoted with $\mathrm{Na}_{2} \mathrm{~S}$ via inorganic ligand exchange at different magnifications.

exposure since no oxidized $S$ species were added during syntheses.

Representative TEM images relevant to catalyst $\mathrm{cFeP} 0.5$ are shown in Figure 1. The NCs distribution on the CNT support and average NC diameter (size statistics from TEM images) do not significantly change after $\mathrm{Na}_{2} \mathrm{~S}$ treatment for $10 \mathrm{~min}$, thereby demonstrating their stability upon inorganic ligand exchange. On the other hand, prolonged mixing of the catalyst powder with the $\mathrm{Na}_{2} \mathrm{~S}$ solution (more than $30 \mathrm{~min}$ ) and heating up of the mixture to $50{ }^{\circ} \mathrm{C}$ led to an aggregation of $\mathrm{Fe}$ NCs (Figure S4). This indicates that the inorganic ligand exchange can impact the stability of Fe-CNT catalysts even in relatively mild conditions.

Recent work on colloidal NC synthesis and processing shows that organic ligands such as oleate could be replaced with charged inorganic species in a ligand-exchange fashion, by mixing a suspension of colloidal NC in apolar solvent with a solution of inorganic ligands in a polar solvent with high dielectric constant. ${ }^{47}$ This procedure can be performed either in solution, where Fe NC stability is preserved by the adsorption of charged species, or with dispersed solids, where NC after deposition on a substrate are exposed to a solution of the inorganic charged ligands. The latter mode of exchange was applied because the NCs were already homogeneously distributed and stabilized on the support.

As a comparison, we used a different procedure by first exchanging oleate with $S^{2-}$ ligands in solution and successively assembling the NCs on CNTs. The iron oxide NC can be successfully transferred to polar formamide by exchanging oleate with $\mathrm{S}^{2-}$ (from $\mathrm{Na}_{2} \mathrm{~S}$ ) ligands in solution. Nevertheless, the NCs formed aggregates rather than assembling homogeneously on the CNTs in formamide (Figure S5). A possible explanation is that charged species at the NC surface shield the van der Waals interaction of NC with the electron-rich CNT surface, so that the NCs just form aggregates upon drying.

STEM-EDX experiments allowed for mapping C, O, Fe, Na, and $S$ through the sample, and a representative EDX map is included in Figure S6. The CNTs were distinguishable by the C mapping, whereas $\mathrm{Fe}$ was present as nanometric iron oxide particles. Oxygen was concentrated where the iron oxide nanoparticles were present. Although $\mathrm{Na}$ and $\mathrm{S}$ were detected by the EDX detector, the concentrations were too low for the detection limit of the instrument.

Reference catalysts (iFe and $\mathrm{iFeP0.5}$ ) were prepared via incipient wetness impregnation, and HAADF-STEM images of iFe and iFeP0.5 are shown in panels $a$ and b of Figure 2, respectively. Figure 2c,d display HAADF-STEM images of
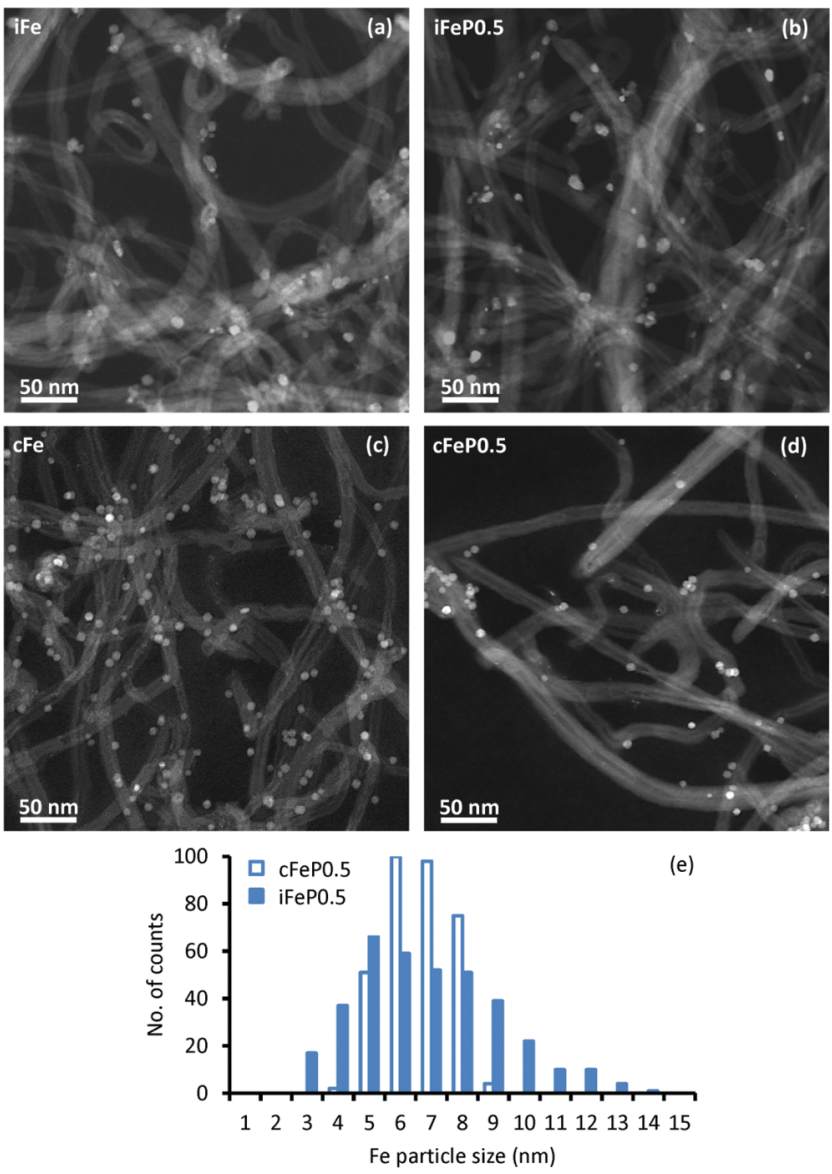

Figure 2. HAADF-STEM images of reference catalysts (a) iFe and (b) iFeP0.5; model catalysts (c) cFe and (d) cFeP0.5; (e) Particle size distributions of iFeP0.5 and $\mathrm{cFeP0}$.5.

colloidal NC catalysts, $c F e$ and cFeP0.5, respectively. $\mathrm{Na}_{2} \mathrm{~S}$ impregnated onto $\mathrm{Fe} \mathrm{NC}$ on $\mathrm{CNT}$ was used to compare with the introduction of $\mathrm{Na}_{2} \mathrm{~S}$ via inorganic ligand exchange. The particle size and particle size distribution did not appear to be changed upon addition of promoters. Although the surface average Fe particle size of IWI and colloidal NC catalysts was similar, the particle size distribution of IWI catalysts was broader (Figure 2e).

The catalytic performance of these Fe-based catalysts under industrially relevant conditions, i.e. $10 \mathrm{bar}$, and $340{ }^{\circ} \mathrm{C}, \mathrm{H}_{2} / \mathrm{CO}$ $=2 \mathrm{v} / \mathrm{v}$ was investigated. Figure 3 displays the catalytic activity as a function of time, thereby providing insights in the stability 


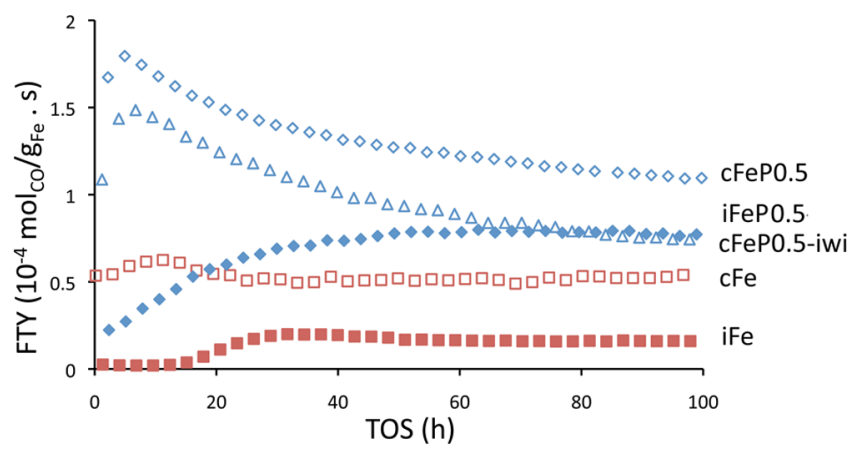

Figure 3. Iron time yield (FTY) vs time on stream (TOS) of unpromoted (red) and promoted (blue) catalysts at $340{ }^{\circ} \mathrm{C}, 10 \mathrm{bar}$, $\mathrm{H}_{2} / \mathrm{CO}=2$ (reference IWI catalysts: solid symbols; model colloidal catalysts: open symbols; promoted catalysts: blue symbols; unpromoted catalysts: red symbols).

of these catalysts at high temperature and pressure. The initial activities of the colloidal catalysts ( $\mathrm{cFe}, \mathrm{cFeP} 0.5$, and cFeP0.5iwi) were higher than the reference IWI catalysts (iFe and

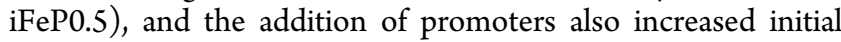
activities.

The general higher activity of colloidal catalysts (cFe over iFe, and both cFeP0.5 and cFeP0.5iwi over iFeP0.5) could be explained by their superior homogeneity, in terms of nanocrystal catalyst size, faceting, distribution on the support, so that the contribution of bigger particles and aggregates can be neglected at the initial stage of the FTO. The higher initial activity of promoted colloidal catalysts compared to promoted catalysts obtained by IWI could be explained accordingly by the more uniform composition of promoters on the catalyst surface. After activation, the unpromoted catalysts ( $\mathrm{cFe}$ and $\mathrm{iFe}$ ) were relatively stable over $100 \mathrm{~h}$. On the other hand, iFeP0.5 showed increasing activity but cFeP0.5 and cFeP0.5-iwi showed decreasing activities. Although both cFeP0.5 and cFeP0.5-iwi deactivated over time, the activity of cFeP0.5 dropped by approximately $33 \%$ and that of cFeP0.5-iwi dropped by approximately 50\%. This suggested that the inorganic ligand exchange approach resulted in a more stable catalyst.

The activities and product selectivities of these catalysts after $100 \mathrm{~h}$ are summarized in Table 2 . The product distribution was similar for the unpromoted catalysts, but the colloidal catalyst cFe was more active than the reference IWI catalyst iFe. After $100 \mathrm{~h}$, the promoted catalysts were more active and more selective toward lower olefins. The catalysts with impregnated

Table 2. Catalytic Performance of Fe-Based CNT-Supported Catalysts under FTO Conditions $\left(340{ }^{\circ} \mathrm{C}, 10 \mathrm{bar}, \mathrm{H}_{2} / \mathrm{CO}=\right.$ 2 , TOS $=100 \mathrm{~h}$ )

\begin{tabular}{|c|c|c|c|c|c|c|c|}
\hline & \multirow[b]{2}{*}{$\begin{array}{l}\mathrm{CO} \\
\text { conv. } \\
(\%)\end{array}$} & \multirow[b]{2}{*}{$\begin{array}{l}\text { FTY }\left(10^{-3}\right. \\
\mathrm{mol}_{\mathrm{CO}} / \mathrm{g}_{\mathrm{Fe}} \\
\mathrm{s})\end{array}$} & \multirow[b]{2}{*}{$\begin{array}{l}\mathrm{CO}_{2} \\
\text { sel. } \\
(\%)\end{array}$} & \multicolumn{4}{|c|}{$\begin{array}{l}\text { product selectivity }\left(\% \mathrm{C}_{\mathrm{at}}\right. \\
\text { hydrocarbons only) }\end{array}$} \\
\hline & & & & $\mathrm{CH}_{4}$ & $\begin{array}{c}\mathrm{C}_{2}- \\
\mathrm{C}_{4} \\
\text { olefins }\end{array}$ & $\begin{array}{l}\mathrm{C}_{2}-\mathrm{C}_{4} \\
\text { paraffins }\end{array}$ & $\mathrm{C}_{5+}$ \\
\hline $\mathrm{iFe}$ & 26 & 0.2 & 32 & 47 & 26 & 21 & 6 \\
\hline $\mathrm{cFe}$ & 21 & 0.5 & 32 & 40 & 27 & 24 & 9 \\
\hline iFeP0.5 & 33 & 0.8 & 39 & 21 & 31 & 30 & 18 \\
\hline $\begin{array}{l}\text { cFeP0.5- } \\
\text { iwi }\end{array}$ & 27 & 0.7 & 37 & 24 & 36 & 26 & 13 \\
\hline cFeP0.5 & 46 & 1.1 & 43 & 13 & 45 & 17 & 26 \\
\hline
\end{tabular}

$\mathrm{Na}$ and $\mathrm{S}$ promoters (iFeP0.5 and $\mathrm{cFeP0.5}$-iwi) showed similar activities and product selectivities. However, the catalyst with $\mathrm{Na}$ and $\mathrm{S}$ promoters introduced via inorganic ligand exchange showed the highest activity and selectivity toward lower olefins.

The improved product selectivity of $\mathrm{cFeP} 0.5$ relative to iFeP0.5 is also evident from the ASF plots (Figure 4) in which
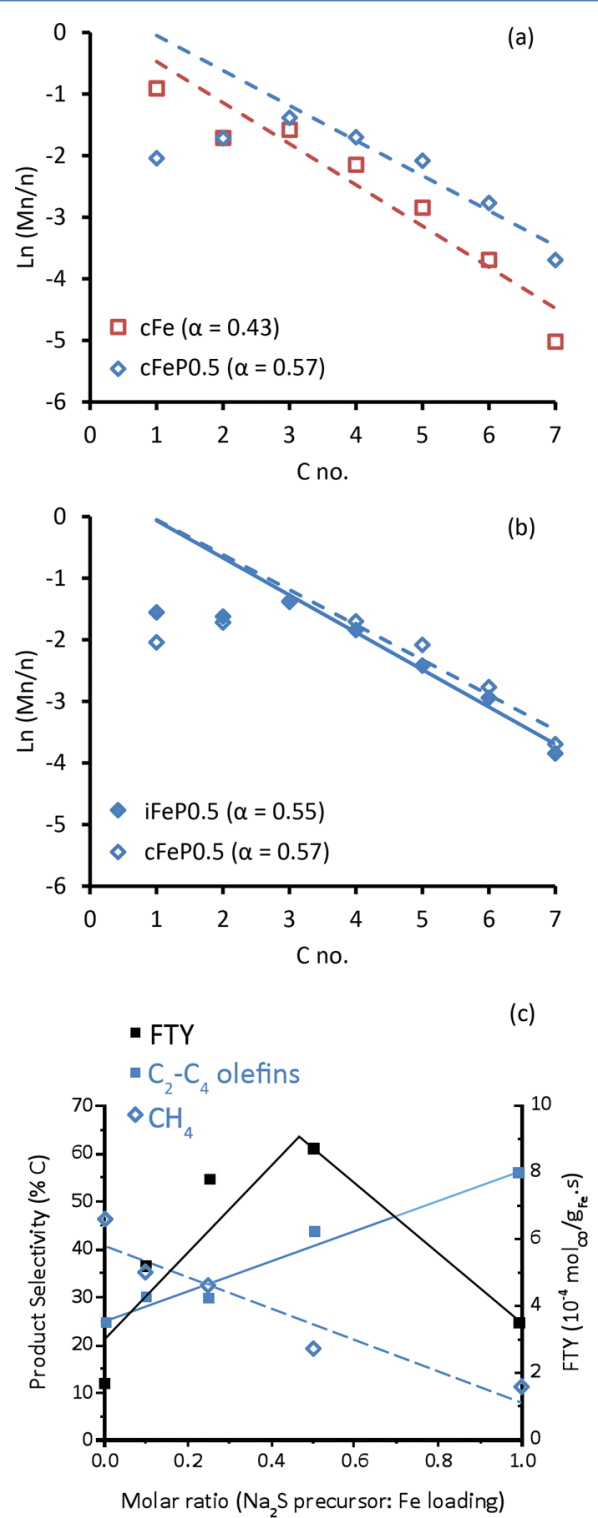

Figure 4. ASF plot of model Fe-based CNT-supported catalysts at 340 ${ }^{\circ} \mathrm{C}, 10$ bar, $\mathrm{H}_{2} / \mathrm{CO} / \mathrm{He}=60 / 30 / 10$ (a) $\mathrm{cFe}$ and $\mathrm{cFeP0} .5$ and (b) iFeP0.5 and cFeP0.5. (c) Effect of molar ratio $\mathrm{Na}_{2} \mathrm{~S}$ precursor solution: Fe loading on activity and product selectivity at $340{ }^{\circ} \mathrm{C}, 10 \mathrm{bar}, \mathrm{H}_{2} /$ $\mathrm{CO}=2$, TOS $=40 \mathrm{~h}$ ). Catalysts $\mathrm{cFe}, \mathrm{cFeP0} 1, \mathrm{cFeP0} 0.25, \mathrm{cFeP0} 0.5$, and $\mathrm{cFeP1} 1.0$.

the $\mathrm{C}_{1}$ fraction deviates from the ASF statistical distribution. The promoted catalysts contained similar level of $\mathrm{Na}$ and $\mathrm{S}$ promoter loadings but displayed different catalytic performances, and this is tentatively proposed to be due to the location of the $\mathrm{Na}$ and $\mathrm{S}$ promoters. $\mathrm{S}^{2-}$ and $\mathrm{NaS}^{-}$ions have a high affinity for the $\mathrm{Fe}^{n+}$-rich $\mathrm{Fe} \mathrm{NC}$ surface and thereby they can replace organic ligands, such as oleate, thus justifying $\mathrm{Na}$ and $\mathrm{S}$ adsorption specifically on the catalytic NC surface. 
Figure $4 \mathrm{c}$ illustrates the influence of the promotion level on the activity and product selectivity at industrially relevant conditions, i.e. $340^{\circ} \mathrm{C}, 10$ bar, $\mathrm{H}_{2} / \mathrm{CO}=2$, GHSV $=3600 \mathrm{~h}^{-1}$. Interestingly, there is an optimum level of promotion at $10 \mathrm{bar}$ which is not apparent at 3 and 5 bar. At 3 and 5 bar, increasing promotion was beneficial for both activity and product selectivity for all promotion levels. However, at 10 bar the activity shows a maximum around 0.6 molar ratio, while a further increase of promoter concentrations does not give rise to activity enhancement but rather reduces the overall activity, albeit producing the highest $\mathrm{C}_{2}-\mathrm{C}_{4}$ selectivity and methane as low as $11 \%$. There is further potential to increase $C_{2}-C_{4}$ olefins selectivity by optimizing the promotion level, while keeping activity high.

The effect of promotion level at varied pressures $(3,5$, and 10 bar) on the Fe NC catalysts was also evaluated. Several observations were made on the effects of promotion level and pressures. First, the increase in pressure led to an increase in activity (Figure S7). Second, the increase in promotion level led to increase in an activity at various pressures, except for the most promoted catalyst, $\mathrm{cFeP} 1.0$ at 10 bar (Figure S7). With increasing pressure, $\mathrm{C}_{2}-\mathrm{C}_{4}$ olefins selectivity decreased while $\mathrm{C}_{2}-\mathrm{C}_{4}$ paraffins selectivity increased (Figure S8). With increasing promotion level, the increase in $\mathrm{C}_{2}-\mathrm{C}_{4}$ olefins selectivity corresponded to an increase in $\mathrm{C}_{5+}$ selectivity and a decrease in $\mathrm{CH}_{4}$ and $\mathrm{C}_{2}-\mathrm{C}_{4}$ paraffins' selectivity (Figure S8). This suppression of methane formation was made evident by the deviation of the $C_{1}$ content from the ASF distribution prediction (Figure S9). Both increase in pressure and addition of $\mathrm{Na}$ and $\mathrm{S}$ promoters increased $\alpha$ (Figure S9).

In situ Mössbauer spectroscopy was carried out for unpromoted $\mathrm{cFe}$ and promoted $\mathrm{cFeP} 0.5$ catalysts at different reaction stages, i.e. after reduction, FTO at 3 and 5 bar, and FTO at 10 bar. Figure 5 summarizes the results on the
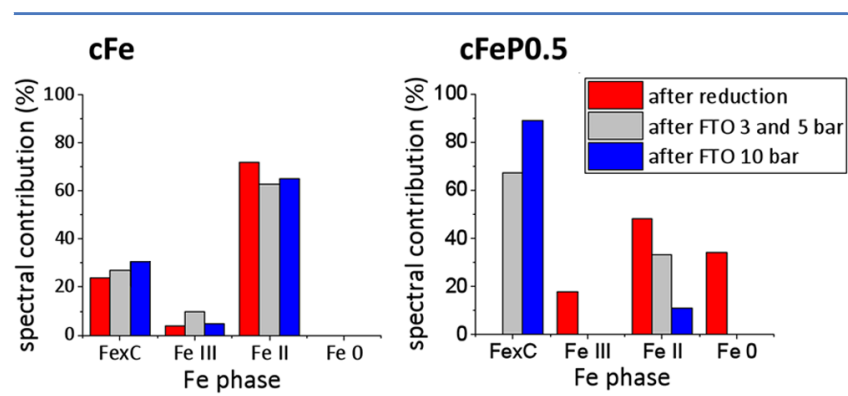

Figure 5. Composition in iron species of unpromoted $\mathrm{cFe}$ (left) and promoted $\mathrm{cFeP} 0.5$ (right) catalysts at different reaction stages, i.e. after reduction (red), FTO at 3 and 5 bar (gray) and FTO at 10 bar (blue) determined by in situ Mössbauer spectroscopy.

composition in iron species of the different catalysts at different reaction stages, while detailed spectra and fits were included as Figure S11 and Table S5, respectively. Both $\mathrm{cFe}$ and $\mathrm{cFeP0.5}$ were partially reduced upon reduction, the latter showing nearly $40 \%$ composition in metallic iron. Upon exposure to synthesis gas at $340{ }^{\circ} \mathrm{C}$ and higher pressure, cFe was partially carbidized and carbidization increased slightly with increase in pressure from 5 to 10 bar. On the other hand, cFeP0.5 was already significantly carburized after exposure to synthesis gas at $340{ }^{\circ} \mathrm{C}$ and higher pressure, the extent of carbidization increasing by increasing the pressure from 5 to 10 bar. Thus, the two key findings from the catalytic tests, i.e. the higher catalytic activity of promoted catalysts and the increased activity of $\mathrm{cFeP} 0.5$ upon increase in pressure from 5 to $10 \mathrm{bar}$, can both be explained by the higher concentration of active iron carbide species of the promoted catalysts compared to their unpromoted counterparts.

The spent catalysts after FTO (TOS $=100 \mathrm{~h}$ ) were characterized with TEM, as shown in Figure 6. All catalysts had
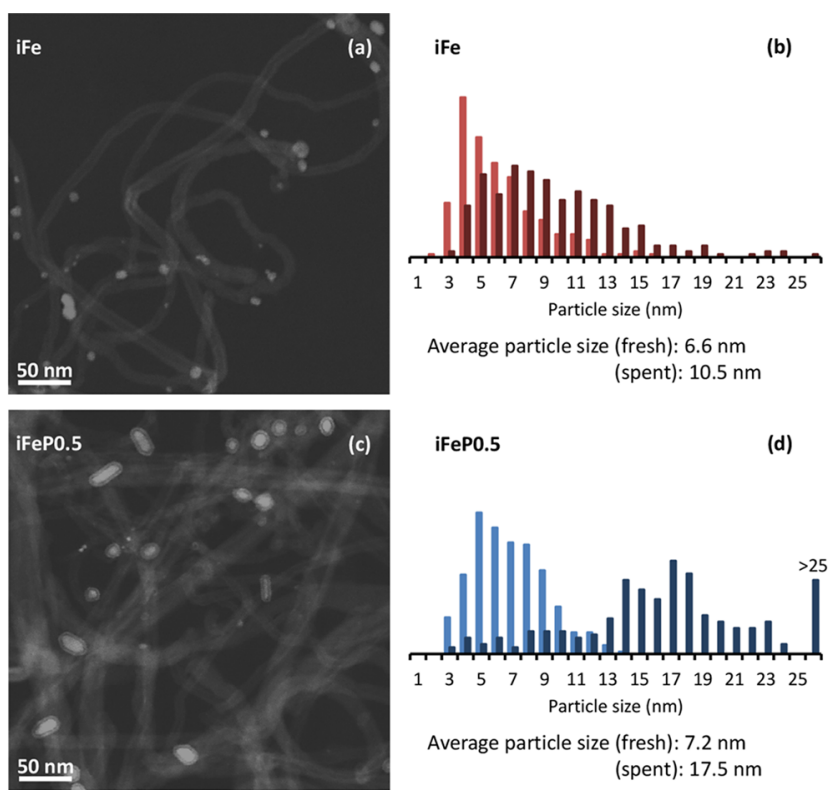

ifeP0.5

(d)
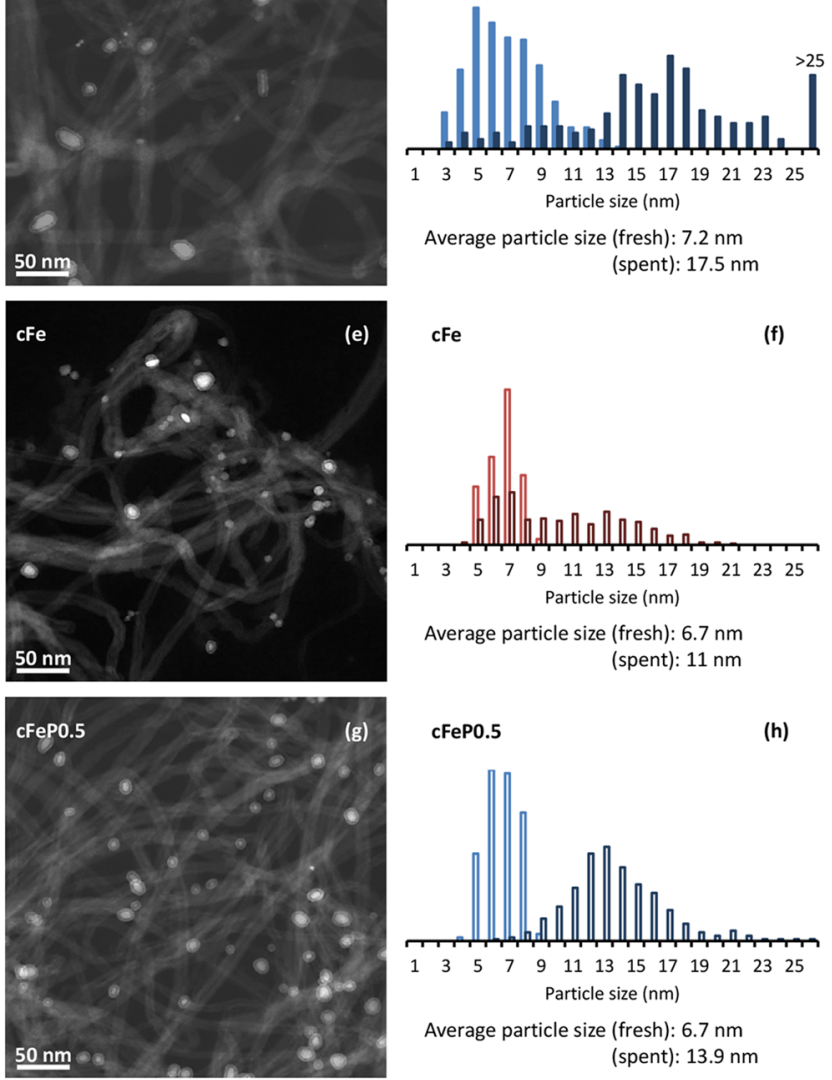

cFe

(f)

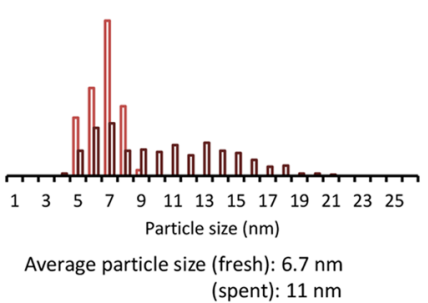

cFePO.5

(h)
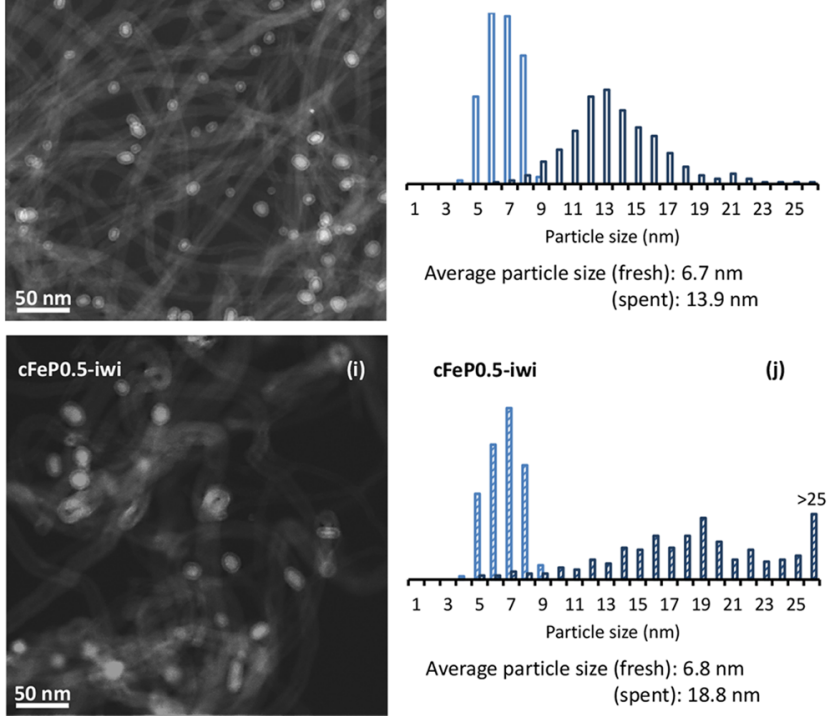

cFeP0.5-iwi

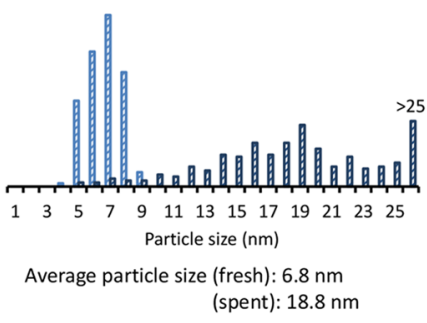

Figure 6. TEM images and particle size distribution of fresh (lighter color) and spent (darker color) catalysts $(\mathrm{a}, \mathrm{b}) \mathrm{iFe},(\mathrm{c}, \mathrm{d})$ iFeP0.5, (e,f) cFe (g,h), cFeP0.5, and (i,j) cFeP0.5. 
similar average particle size after synthesis as mentioned earlier, albeit broader particle size distributions were measured for iFe and iFeP0.5. However, the particle size distributions of spent catalysts were remarkably different. For the unpromoted catalysts (iFe and $\mathrm{cFe}$ ), average $\mathrm{Fe}$ nanoparticles grew from 7 to $11 \mathrm{~nm}$ upon FTO reaction. Notably, the spent catalyst cFe possessed a bimodal particle size distribution in comparison to iFe. For the catalysts promoted via impregnation (iFeP0.5 and cFeP0.5-iwi), average Fe nanoparticles grew from 7 to $18 \mathrm{~nm}$ upon FTO reaction, and there were significant number of $\mathrm{Fe}$ nanoparticles larger than $25 \mathrm{~nm}$. For the catalyst promoted via inorganic ligand exchange ( $\mathrm{cFeP0} .5$ ), average $\mathrm{Fe}$ nanoparticles grew from 7 to $14 \mathrm{~nm}$ upon FTO reaction, and no $\mathrm{Fe}$ nanoparticles larger than $25 \mathrm{~nm}$ were observed. In addition, the spent catalyst of $\mathrm{cFeP0.5}$ had the narrowest particle size distribution. Thus, growth of Fe nanoparticles appeared to be less when $\mathrm{Na}$ and $\mathrm{S}$ promoters were introduced via inorganic ligand exchange, and this is in good agreement with the constant trend of the catalyst activity over time (Figure 3).

The size and promoter effects on stability were previously investigated and $\mathrm{Fe}$ particle growth was proposed to be the main cause of deactivation for the promoted catalysts. With reference to Figure S12, this current study reiterates the preposition that loss of active Fe surface area resulted in loss of activity. ${ }^{57}$

\section{CONCLUSION}

A novel approach toward promoter incorporation in metal nanocrystal catalysts was presented, and Fe-based FTO catalysts were used as a showcase. New FTO catalysts were synthesized based on colloidal NCs in which promoters are adsorbed on the surface of catalyst NCs via ligand exchange. This method conveniently eliminates organic ligands, which could interfere in the catalytic FT process, and more importantly allows for active catalysts with a controlled amount of promoters to be synthesized. Catalysts with different amounts of promoters were tested under industrially relevant FT conditions at different pressures and the process was optimized to achieve the best combination of activity and product selectivity. These colloidal-based catalysts outperformed catalysts with similar composition but synthesized with conventional coimpregnation methods.

A correlation of these data with in situ Mössbauer spectroscopy and ex situ microscopy revealed that promoted colloidal catalysts are more stable, easier to reduce and covert into active carbide species, possibly due to the close contact of the promoters with the iron catalyst.

These results suggest that wet chemical methods, such as the combination of colloidal synthesis, assembly and ligand exchange approaches, are a viable route to fabricate heterogeneous catalysts with superior properties control. The development of stable catalysts with controlled characteristics acting as a model system is an essential step toward understanding structure and composition-related catalytic features. Notably, the method described was applied to an extremely complex catalytic system, since iron catalysts undergo severe transformations in the course of a FTO process, but could be further extended to several NC catalyst systems and types of promoters. In addition, this preliminary study strengthens the idea that recent achievements in the liganddriven chemistry, such as controlling the number and the position of heteroatoms on specific NC facets, could be applied to manipulate the composition, and thus the reactivity, of catalytic surfaces.

\section{ASSOCIATED CONTENT}

S Supporting Information

The Supporting Information is available free of charge on the ACS Publications website at DOI: 10.1021/acscatal.7b00847.

ICP-AES, TEM, XPS, catalyst performance, and in situ Mössbauer spectroscopy (PDF)

\section{AUTHOR INFORMATION}

\section{Corresponding Author}

*E-mail: k.p.dejong@uu.nl.

ORCID 1

Marianna Casavola: 0000-0002-8902-7431

Jan P. Hofmann: 0000-0002-5765-1096

Present Address

$\perp$ (M.C.) Department of Physics, King's College London

\section{Author Contributions}

${ }^{\dagger}$ M.C. and J.X. contributed equally.

\section{Notes}

The authors declare no competing financial interest.

\section{ACKNOWLEDGMENTS}

This research received funding from The Netherlands Organization for Scientific Research (NWO) in the framework of the TASC Technology Area "Syngas, a Switch to Flexible New Feedstock for the Chemical Industry (TA-Syngas)". Dow and Johnson Matthey are also acknowledged for the funding received. K.P.d.-J. acknowledges the European Research Council, EU FP7 ERC Advanced Grant no. 338846. H. C. de Waard (Utrecht University) is acknowledged for ICP measurements. Dr. M. Ruitenbeek (Dow), Dr. M. Watson (J.P.M.) and Dr. L. van der Water (J.P.M.) are thanked for fruitful discussion.

\section{REFERENCES}

(1) White, R. J.; Luque, R.; Budarin, V. L.; Clark, J. H.; Macquarrie, D. J. Chem. Soc. Rev. 2009, 38, 481-494.

(2) Zecevic, J.; Vanbutsele, G.; de Jong, K. P.; Martens, J. A. Nature 2015, 528, 245-248.

(3) Tuček, J.; Sofer, Z.; Bouša, D.; Pumera, M.; Holá, K.; Malá, A.; Poláková, K.; Havrdová, M.; Čépe, K.; Tomanec, O.; Zbořil, R. Nat. Commun. 2016, 7, 12879.

(4) Schwarz, J. A.; Contescu, C.; Contescu, A. Chem. Rev. 1995, 95, 477-510.

(5) Lykhach, Y.; Kozlov, S. M.; Skála, T.; Tovt, A.; Stetsovych, V.; Tsud, N.; Dvořák, F.; Johánek, V.; Neitzel, A.; Mysliveček, J.; Fabris, S.; Matolín, V.; Neyman, K. M.; Libuda, J. Nat. Mater. 2016, 15, 284288.

(6) Matsubu, J. C.; Zhang, S.; DeRita, L.; Marinkovic, N. S.; Chen, J. G.; Graham, G. W.; Pan, X.; Christopher, P. Nat. Chem. 2016, 9, 120127.

(7) van den Berg, R.; Prieto, G.; Korpershoek, G.; van der Wal, L. I.; van Bunningen, A. J.; Lægsgaard-Jørgensen, S.; de Jongh, P. E.; de Jong, K. P. Nat. Commun. 2016, 7, 13057.

(8) Munnik, P.; de Jongh, P. E.; de Jong, K. P. Chem. Rev. 2015, 115, 6687-6718.

(9) Hutchings, G. J. Catal. Lett. 2001, 75, 1-12.

(10) McCue, A. J.; Anderson, J. A. Catal. Sci. Technol. 2014, 4, 272294. 
(11) Feltes, T. E.; Espinosa-Alonso, L.; de Smit, E.; D'Souza, L.; Meyer, R. J.; Weckhuysen, B. M.; Regalbuto, J. R. J. Catal. 2010, 270, 95-102.

(12) Gauthard, F.; Epron, F.; Barbier, J. J. Catal. 2003, 220, 182-191.

(13) Dieterle, M.; Schwab, E. Top. Catal. 2016, 59, 817.

(14) Higman, C.; Tam, S. Chem. Rev. 2014, 114, 1673-1708.

(15) Lanzafame, P.; Centi, G.; Perathoner, S. Chem. Soc. Rev. 2014, $43,7562-7580$.

(16) Khodakov, A. Y.; Chu, W.; Fongarland, P. Chem. Rev. 2007, 107, 1692-1744.

(17) Zhang, Q.; Kang, J.; Wang, Y. ChemCatChem 2010, 2, 10301058

(18) Xiang, Y.; Kruse, N. Nat. Commun. 2016, 7, ArticleNo. 13058.

(19) Olsbye, U.; Svelle, S.; Bjørgen, M.; Beato, P.; Janssens, T. V. W.; Joensen, F.; Bordiga, S.; Lillerud, K. P. Angew. Chem., Int. Ed. 2012, 51, $5810-5831$.

(20) Tian, P.; Wei, Y.; Ye, M.; Liu, Z. ACS Catal. 2015, 5, 19221938.

(21) Jiao, F.; Li, J.; Pan, X.; Xiao, J.; Li, H.; Ma, H.; Wei, M.; Pan, Y.; Zhou, Z.; Li, M.; et al. Science 2016, 351, 1065-1068.

(22) Cheng, K.; Gu, B.; Liu, X.; Kang, J.; Zhang, Q.; Wang, Y. Angew. Chem., Int. Ed. 2016, 55, 4725-4728.

(23) Torres Galvis, H. M.; de Jong, K. P. ACS Catal. 2013, 3, 21302149

(24) van der Laan, G. P.; Beenackers, A. A. C. M. Catal. Rev.: Sci. Eng. 1999, 41, 255-318.

(25) van Santen, R. A.; Ghouri, M. M.; Shetty, S.; Hensen, E. M. H. Catal. Sci. Technol. 2011, 1, 891-911.

(26) Torres Galvis, H. M.; Bitter, J. H.; Khare, C. B.; Ruitenbeek, M.; Dugulan, A. I.; de Jong, K. P. Science 2012, 335, 835-838.

(27) Xie, J.; Yang, J.; Dugulan, A. I.; Holmen, A.; Chen, D.; de Jong, K. P.; Louwerse, M. J. ACS Catal. 2016, 6, 3147-3157.

(28) Zhong, L.; Yu, F.; An, Y.; Zhao, Y.; Sun, Y.; Li, Z.; Lin, T.; Lin, Y.; Qi, X.; Dai, Y.; Gu, L.; Hu, J.; Jin, S.; Shen, Q.; Wang, H. Nature 2016, 538, 84-87.

(29) Cheng, K.; Ordomsky, V. V.; Legras, B.; Virginie, M.; Paul, S.; Wang, Y.; Khodakov, A. Y. Appl. Catal., A 2015, 502, 204-214.

(30) Wang, D.; Ji, J.; Chen, B.; Chen, W.; Qian, G.; Duan, X.; Zhou, X.; Holmen, A.; Chen, D.; Walmsley, J. C. AIChE J. 2017, 63, 154161.

(31) Chonco, Z. H.; Ferreira, A.; Lodya, L.; Claeys, M.; van Steen, E. J. Catal. 2013, 307, 283-394.

(32) Botes, G. F.; Bromfield, T. C.; Coetzer, R. L. J.; Crous, R.; Gibson, P.; Ferreira, A. C. Catal. Today 2016, 275, 40-48.

(33) Yin, Y.; Alivisatos, a P. Nature 2005, 437, 664-670.

(34) He, R.; Wang, Y.; Wang, X.; Wang, Z.; Liu, G.; Zhou, W.; Wen, L.; Li, Q.; Wang, X.; Chen, X.; Zeng, J.; Hou, J. G. Nat. Commun. 2014, 5, 4327.

(35) Cho, E. S.; Ruminski, A. M.; Aloni, S.; Liu, Y.-S.; Guo, J.; Urban, J. J. Nat. Commun. 2016, 7, 10804.

(36) Sayevich, V.; Cai, B.; Benad, A.; Haubold, D.; Sonntag, L.; Gaponik, N.; Lesnyak, V.; Eychmüller, A. Angew. Chem., Int. Ed. 2016, 55, 6334-6338.

(37) Khan, M. U.; Wang, L.; Liu, Z.; Gao, Z.; Wang, S.; Li, H.; Zhang, W.; Wang, M.; Wang, Z.; Ma, C.; Zeng, J. Angew. Chem., Int. Ed. 2016, 55, 9548-9552.

(38) Loiudice, A.; Lobaccaro, P.; Kamali, E. A.; Thao, T.; Huang, B. H.; Ager, J. W.; Buonsanti, R. Angew. Chem., Int. Ed. 2016, 55, 57895792 .

(39) Cargnello, M.; Doan-Nguyen, V. V. T.; Gordon, T. R.; Diaz, R. E.; Stach, E. a.; Gorte, R. J.; Fornasiero, P.; Murray, C. B. Science 2013, 341, 771-773.

(40) Casavola, M.; Hermannsdörfer, J.; de Jonge, N.; Dugulan, A. I.; de Jong, K. P. Adv. Funct. Mater. 2015, 25, 5309-5319.

(41) Rosen, E. L.; Buonsanti, R.; Llordes, A.; Sawvel, A. M.; Milliron, D. J.; Helms, B. A. Angew. Chem., Int. Ed. 2012, 51, 684-689.

(42) Luz, I.; Loiudice, A.; Sun, D. T.; Queen, W. L.; Buonsanti, R. Chem. Mater. 2016, 28, 3839-3849.
(43) Boles, M. A.; Ling, D.; Hyeon, T.; Talapin, D. V. Nat. Mater. 2016, 15, 141-153.

(44) De Roo, J.; Van Driessche, I.; Martins, J. C.; Hens, Z. Nat. Mater. 2016, 15, 517-521.

(45) Pellegrino, T.; Manna, L.; Kudera, S.; Liedl, T.; Koktysh, D.; Rogach, A. L.; Keller, S.; Rädler, J.; Natile, G.; Parak, W. J. Nano Lett. 2004, 4, 703-707.

(46) Llordés, A.; Garcia, G.; Gazquez, J.; Milliron, D. J. Nature 2013, $500,323-326$.

(47) Kovalenko, M. V.; Scheele, M.; Talapin, D. V. Science 2009, 324, 1417-1420.

(48) Singh, A.; Lindquist, B. A.; Ong, G. K.; Jadrich, R. B.; Singh, A.; Ha, H.; Ellison, C. J.; Truskett, T. M.; Milliron, D. J. Angew. Chem., Int. Ed. 2015, 54, 14840-14844.

(49) Nag, A.; Kovalenko, M. V.; Lee, J.; Liu, W.; Spokoyny, B.; Talapin, D. V. J. Am. Chem. Soc. 2011, 133, 10612-10620.

(50) Sun, S.; Zeng, H.; Robinson, D. B.; Raoux, S.; Rice, P. M.; Wang, S. X.; Li, G. J. Am. Chem. Soc. 2004, 126, 273-279.

(51) Buonsanti, R.; Grillo, V.; Carlino, E.; Giannini, C.; Curri, M. L.; Innocenti, C.; Sangregorio, C.; Achterhold, K.; Parak, F. G.; Agostiano, A.; Cozzoli, P. D. J. Am. Chem. Soc. 2006, 128, 16953-16970.

(52) Cabot, A.; Puntes, V. F.; Shevchenko, E.; Yin, Y.; Balcells, L.; Marcus, M. A.; Hughes, S. M.; Alivisatos, A. P. J. Am. Chem. Soc. 2007, 129, 10358-10360.

(53) Di Corato, R.; Piacenza, P.; Musaro, M.; Buonsanti, R.; Cozzoli, P. D.; Zambianchi, M.; Barbarella, G.; Cingolani, R.; Manna, L.; Pellegrino, T. Macromol. Biosci. 2009, 9, 952-958.

(54) Ritz, B.; Heller, H.; Myalitsin, A.; Kornowski, A.; Martinmartinez, F. J.; Melchor, S.; Dobado, J. A.; Juarez, B. H.; Weller, H.; Klinke, C. ACS Nano 2010, 4, 2438-2444.

(55) Klencsár, Z. Nucl. Instrum. Methods Phys. Res., Sect. B 1997, 129, $527-533$.

(56) Wezendonk, T. A.; Santos, V. P.; Nasalevich, M. A.; Warringa, Q. S. E.; Dugulan, A. I.; Chojecki, A.; Koeken, A. C. J.; Ruitenbeek, M.; Meima, G.; Islam, H.; Sankar, G.; Makkee, M.; Kapteijn, F.; Gascon, J. ACS Catal. 2016, 6, 3236-3247.

(57) Xie, J.; Torres Galvis, H. M.; Koeken, A. C. J.; Kirilin, A.; Dugulan, A. I.; Ruitenbeek, M.; de Jong, K. P. ACS Catal. 2016, 6, 4017-4024. 